\title{
Arterial properties in adults with long- lasting active juvenile idiopathic arthritis compared to healthy controls
}

\author{
Hanne Aaserud Aulie ${ }^{1,2^{*}}$ D , Mette-Elise Estensen ${ }^{3}$, Anne Marit Selvaag ${ }^{1}$, Vibke Lilleby ${ }^{1}$, Berit Flat $\varnothing^{1,4}$ \\ and Svend Aakhus $5^{5,6}$
}

\begin{abstract}
Background: The data on cardiovascular risk and systemic arterial properties in patients with long-lasting juvenile idiopathic arthritis (JIA) is limited. The objective of this study was to describe systemic arterial properties including characteristic impedance $\left(Z_{0}\right)$, total arterial compliance $(C)$, and peripheral vascular resistance $(R)$ in patients with long-lasting active JIA compared with matched controls, and to assess the relation to JIA disease variables and traditional cardiovascular risk factors.

Findings: Methods: Eighty-one JIA patients (median age 38.6) with at least 15 years of active disease were reexamined after median 29 years of disease duration and compared to 41 healthy controls. With use of echocardiography and calibrated right common carotid artery tonometric pulse traces, noninvasive estimates of pressure and blood flow from the aortic root were obtained and used to estimate the systemic arterial parameters $Z_{0,} C$ and $R$. Results: The patients had higher $Z_{0}$ as assessed by Windkessel model (mean \pm SD $65.0 \pm 30.1$ versus $53.4 \pm 18.810^{-3}$ $\mathrm{mmHg} / \mathrm{ml} / \mathrm{s}, p=0.027)$, lower $C$ as assessed by either Windkessel model or ratio of stroke volume and pulse pressure (1. $57 \pm 0.46$ versus $1.80 \pm 0.65 \mathrm{ml} / \mathrm{mmHg}, p=0.030,1.29 \pm 0.37$ versus $1.43 \pm 0.34 \mathrm{ml} / \mathrm{mmHg}, p=0.038$ ), and similar $R$ compared to the controls. Years on daily prednisolone and insulin resistance were the most important correlates of $Z_{0}$. Metotrexat use, polyarticular disease course and erythrocyte sedimentation rate were also associated with a higher $Z_{0}$.

Conclusion: Our results indicate that JIA patients had altered arterial properties as compared to controls. Years on daily prednisolone and insulin resistance were the most important correlates of altered arterial properties.
\end{abstract}

Keywords: Juvenile idiopathic arthritis, Inflammation, Cardiovascular disease, Arterial stiffness

\section{Introduction}

Juvenile idiopathic arthritis (JIA) is a chronic inflammatory rheumatic disease with symptom onset in childhood and persists into adulthood in about $50 \%$ of the patients $[1,2]$.

Arterial stiffness is an established independent predictor of cardiovascular disease (CVD) [3]. Whereas adult onset inflammatory arthritis is known to be related to increased arterial stiffness [4], little is known of systemic arterial properties and cardiovascular risk in those with long-lasting JIA.

\footnotetext{
* Correspondence: hanneaulie@hotmail.com

${ }^{1}$ Department of Rheumatology, Oslo University Hospital, Rikshospitalet, Oslo, Norway

${ }^{2}$ Department of Internal Medicine, Diakonhjemmet Hospital, Oslo, Norway Full list of author information is available at the end of the article
}

Pulse wave velocity (PWV) is the most frequently used method for the measurement of arterial stiffness reflecting large arterial stiffness [5]. However, the properties of the arterial system can be described in more detail by use of system level parameters, as characteristic impedance $\left(Z_{0}\right)$, arterial compliance $(C)$ and vascular resistance $(R)[6]$.

We have previously reported an increased prevalence of hypertension and arterial stiffness as measured by PWV in adults with long-lasting active JIA [7]. However, $\mathrm{Z}_{0}, \mathrm{C}$ and $\mathrm{R}$ have hitherto not been described in this patient group. The present study was therefore designed to characterize systemic arterial properties in detail in JIA patients as compared to matched controls. We also wanted to assess the associations between JIA disease variables, cardiovascular risk factors and arterial properties. 


\section{Methods}

\section{Patients and controls}

Totally 134 JIA patients with clinically active disease for at least 15 years of disease duration were invited to a combined rheumatologic and cardiologic follow-up study after median 29 years. The patients were initially referred to the Oslo University hospital between 1980 and 85, and re-examined after median 15 and 23 years before the present study [2]. Between May 2011 and March 2012, 90 patients were included in the study. Nine were excluded after inclusion due to pregnancy $(n=3)$, recordings of suboptimal quality $(n=5)$, or severe heart disease without presumed relation to JIA $(n=1)$. The 81 participants were not different from the 53 eligible but not participating patients regarding gender, disease duration and age (data not shown).

Forty-six healthy, age- and gender-matched controls were selected randomly from the Norwegian population register. Responders with a history of diabetes mellitus, hypertension, or inflammatory arthritis were not included. Five were excluded after inclusion due to suboptimal recordings.

\section{Clinical examination and cardiovascular risk assessments}

The 81 patients underwent a clinical examination performed by a specialist in rheumatology, the controls were clinically examined by a physician.

JIA was classified according to the International League of Associations for Rheumatology criteria [8]. Active disease was defined as the lack of remission off anti-rheumatic medication [9].

Family history of CVD was defined as a first degree having CVD before the age of 65 (women) and 55 (men). Information about smoking habits and physical activity was obtained through a questionnaire. Insulin resistance was derived from the assessments of insulin and glucose [10].

Three measurements of systolic blood pressure (SBP) and diastolic blood pressure (DBP) with a difference of $<5 \mathrm{mmHg}$ were averaged and taken in all participants after $5 \mathrm{~min}$ rest in a supine position. Arterial hypertension was defined as $\mathrm{SBP}>140 \mathrm{mmHg}$ and/or $\mathrm{DBP}>90$ $\mathrm{mmHg}$, and/or use of antihypertensive medication.

Blood samples were drawn after an overnight fast and analysed for high sensitive C-reactive protein (CRP), erythrocyte sedimentation rate (ESR), insulin, glucose and cholesterol.

\section{Non-invasive assessment of arterial properties Tonometry}

We recorded the arterial pulse waveform from the right common carotid artery with the patient in a supine position, using a high-fidelity external applanation tonometric device (Millar SPT-301, Millar Instruments Inc., Houston,
USA). Recordings were obtained semi-simultaneously with echocardiographic doppler recordings (Vivid 7 ultrasound scanner, GE Vingmed ultrasound, Norway) of blood flow from the left ventricular outflow tract and the parasternal short axis midventricular cineloops. The tonometric signal was amplified and transferred to a personal computer for processing in Matlab 7 application [11]. We selected at least three cardiac cycles for analysis. The carotid pulse trace peak and nadir were then calibrated with the systolic and diastolic brachial arterial pressures, respectively.

\section{Systemic arterial properties}

A 3-element electrical analogue Windkessel model of the systemic circulation was used to assess $Z_{0}, R$ and $C$ [11]. In order to obtain estimates of systemic parameters independent of any assumed model, we also assessed $\mathrm{Z}_{0}$ in the frequency domain as the average of the high frequency harmonics of the input impedance modulus [6]. C was also estimated as stroke volume $(\mathrm{mL})$ over arterial pulse pressure ( $\mathrm{mmHg}$ ).

\section{Statistics}

The JIA patients and controls, and the patient subgroups were compared using a 2-sided independent sample $t$-test for the continuous normally distributed variables, the Mann-Whitney $U$-test for the continuous not normally distributed values, and the $x^{2}$ test for the categorical variables. For the continuous normally distributed variables, central tendencies were given as the mean $\pm \mathrm{SD}$ and for the continuous not normally distributed values, median inter-quartile range. A $p$ value $<0.05$ (2 tailed) were regarded as statistically significant for all the analyses. Pearson's Correlation coefficients and multivariate linear regression analysis were used to investigate associations between disease variables, cardiovascular risk factors and arterial properties. SPSS Version 20 (SPSS, Chicago, USA) was used for the statistical analyses.

\section{Results}

\section{Demographics and cardiovascular risk factors}

The characteristics of patients and controls are summarized in Table 1 . Hypertension was present in $11 \%$ of the patients, and in none of the controls $(p=0.028)$.

\section{Systemic arterial properties}

$\mathrm{Z}_{0}$ estimated by Windkessel model was significantly higher $(21.7 \%, p=0.027$, Table 2$)$ in the patients, and $\mathrm{Z}_{0}$ by frequency domain analyses although numerically higher in the patients, the difference was not statistically different between the groups. $\mathrm{C}$ by either of Windkessel model or ratio of stroke volume and pulse pressure was significantly lower in the patients compared to controls 
Table 1 JIA disease characteristics and traditional cardiovascular risk factors

\begin{tabular}{|c|c|c|}
\hline Variables & JIA patients $(n=81)$ & Controls $(n=41)$ \\
\hline \multicolumn{3}{|l|}{ Demographics } \\
\hline Male gender; n (\%) & $20(25)$ & $9(22)$ \\
\hline Age (years); median (IQR) & $38.6(34.9-40.7)$ & $37.7(34.8-40.5)$ \\
\hline Disease duration (years); median (IQR) & $29.3(28.3-30.6)$ & \\
\hline Onset age (years); median (IQR) & $8.9(4.9-11.8)$ & \\
\hline \multicolumn{3}{|l|}{ JIA subtype distribution } \\
\hline Systemic arthritis; n (\%) & $4(5)$ & \\
\hline RF negative polyarthritis; n (\%) & $11(14)$ & \\
\hline RF positive polyarthritis; n (\%) & $5(6)$ & \\
\hline Persistent oligoarthritis; n (\%) & $14(17)$ & \\
\hline Extended oligoarthritis; n (\%) & $13(16)$ & \\
\hline Entesitis related arthritis; n (\%) & $18(22)$ & \\
\hline Psoriatic arthritis; n (\%) & $14(17)$ & \\
\hline Unclassified arthritis; n (\%) & $2(3)$ & \\
\hline \multicolumn{3}{|l|}{ Current medication at 29-year follow-up } \\
\hline Anti-TNF; n (\%) & $25(31)$ & \\
\hline Metotrexat; n (\%) & $19(24)$ & \\
\hline NSAIDs daily; n (\%) & $23(28)$ & \\
\hline Prednisolone; n (\%) & $5(6.2)$ & \\
\hline \multicolumn{3}{|l|}{ Cardiovascular risk factors } \\
\hline BMI $\left(\mathrm{kg} / \mathrm{m}^{2}\right)$; mean $(\mathrm{SD})$ & $25.7(5.0)$ & $25.3(3.9)$ \\
\hline Waist circumference (cm); mean (SD) & $92.7(12.7)$ & $92.7(9.0)$ \\
\hline Daily smokers; n (\%) & $18(22)$ & $5(12)$ \\
\hline CVD in first degree relative; $\mathrm{n}(\%)$ & $46(57)$ & $19(46)$ \\
\hline Hypertension; n (\%) & $9(11)$ & $0(0)^{*}$ \\
\hline Myocardial infarction; n (\%) & $1(1)$ & $0(0)$ \\
\hline Total cholesterol (mmol/L); mean (SD) & $4.9(1.1)$ & $4.9(0.8)$ \\
\hline LDL cholesterol (mmol/L); mean (SD) & $3.0(1.0)$ & $3.0(0.8)$ \\
\hline hs-CRP (mg/L); median (IQR) & $1.8(0.7-5.0)$ & $0.7(0.0-1.9)^{*}$ \\
\hline Insulin resistance & $1.1(1.1)$ & $0.9(0.6)$ \\
\hline
\end{tabular}

$J A$ Juvenile idiopathic arthritis, IQR inter-quartile range, $R F$ rheumatoid factor, anti-TNF anti-tumor necrosis factor, NSAIDs nonsteroidal anti-inflammatory drugs, $B M I$ body mass index, $L D L$ low density lipoprotein, $C V D$ cardiovascular disease, $h s-C R P$ high sensitivity C-reactive protein * $p<0.05$ compared with values in previous column

(12.8 and $9.8 \%, p=0.030$ and $p=0.038$, respectively). Heart rate was slightly higher in the patients $(p=0.026)$, however $\mathrm{R}$ was similar in patients and controls.

The association between JIA disease variables, cardiovascular risk factors and systemic arterial properties $\mathrm{Z}_{0}$ by Windkessel model was significantly higher in the patients with present or previous use of metotrexat, using prednisolone, and/or had polyarticular disease course as compared to the other patients (Fig. 1), and was correlated to higher ESR area under the curve (AUC), years on daily prednisolone and insulin resistance (Table 3). When including these variables in a multiple linear regression analysis, years on daily prednisolone and insulin resistance were determinants of $\mathrm{Z}_{0}$ $(ß=0.003, p=0.021, \beta=0.006, p=0.042)$.

\section{Findings}

The present long-term follow-up study indicates that JIA patients with long-term active disease have altered systemic arterial properties as demonstrated by a higher $\mathrm{Z}_{0}$ by Windkessel and a lower $\mathrm{C}$ when compared to controls. Years on daily prednisolone and insulin resistance were the most important correlates of $\mathrm{Z}_{0}$. Furthermore, the use of metotrexat, polyarticular disease course and ESR AUC correlated with higher $\mathrm{Z}_{0}$. 
Table 2 Arterial haemodynamics and arterial properties

\begin{tabular}{|c|c|c|c|c|}
\hline Variables & JIA Patients $(n=81)$ & Controls $(n=41)$ & Difference (\%) & $P$-value \\
\hline Height, cm & $170.5(8.4)$ & $170.3(8.3)$ & 0 & 0.881 \\
\hline Weight, kg & $74.9(16.7)$ & $73.3(12.1)$ & 2.2 & 0.603 \\
\hline Heart rate, beats/minute & $65(11)$ & $61(9)$ & 6.6 & 0.026 \\
\hline Systolic blood pressure, $\mathrm{mmHg}$ & $119(18)$ & $113(11)$ & 5.3 & 0.054 \\
\hline Diastolic blood pressure, $\mathrm{mmHg}$ & $70(10)$ & $67(9)$ & 4.5 & 0.091 \\
\hline Mean arterial pressure; $\mathrm{mmHg}$ & $90(13)$ & $85(9)$ & 5.9 & 0.026 \\
\hline $\mathrm{R}, \mathrm{mm} \mathrm{Hg} / \mathrm{ml} / \mathrm{s}$ & $1.02(0.27)$ & $1.00(0.22)$ & 0.02 & 0.636 \\
\hline $\mathrm{CWK}, \mathrm{ml} / \mathrm{mm} \mathrm{Hg}$ & $1.57(0.46)$ & $1.80(0.65)$ & 12.8 & 0.030 \\
\hline C SV/PP, $\mathrm{ml} / \mathrm{mmHg}$ & $1.29(0.37)$ & $1.43(0.34)$ & 9.8 & 0.038 \\
\hline $\mathrm{Z}_{0} \mathrm{WK}, 10^{-3} \mathrm{mmHg} / \mathrm{ml} / \mathrm{s}$ & $65.0(30.1)$ & $53.4(18.8)$ & 21.7 & 0.027 \\
\hline$Z_{0} F D$ & $96.1(37.2)$ & $91.5(31.4)$ & 5.0 & 0.497 \\
\hline
\end{tabular}

Values are the mean (SD)

$R$ total peripheral resistance, $C W K$ compliance estimated by Windkessel model, $C$ SV/PP compliance estimated as ratio of stroke volume and pulse pressure, $Z_{0} W K$ characteristic impedance estimated by Windkessel model, $Z_{O} F D$ characteristic impedance estimated by frequency domain analyses

Whereas $Z_{0}$ reflects the combined effect of size and stiffness (a high $\mathrm{Z}_{0}$ implies a stiffer and/or small sized aorta) of predominantly the ascending aorta, $\mathrm{C}$ reflects the volume compliance of the entire systemic arterial tree. $\mathrm{R}$ is mainly determined by the small muscular arterioles [6]. Considering both $\mathrm{C}$ and the $\mathrm{Z}_{0}$ by Windkessel, our findings suggest that the central conduit arteries are altered more than peripheral arteries in adult JIA patients. Previous reports have emphasized the importance of large arterial stiffness rather than alterations of microvascular resistance in the prediction of cardiovascular risk in patients with hypertension [12, 13]. Importantly, lower C and higher $Z_{0}$ are associated with increased cardiovascular risk in the adult general population $[14,15]$.

Our data support a previous study from the same patient cohort, showing higher PWV in adult JIA patients compared to controls [7]. Thus, increased arterial stiffness has been demonstrated to be present by different noninvasive techniques in JIA patients.

In the patient group, 8 had hypertension while controls with hypertension were excluded in order to maintain a healthy control group. However, when compared to controls, the differences in SBP and DBP were only marginal numerically, and not of statistical significance. Thus, we

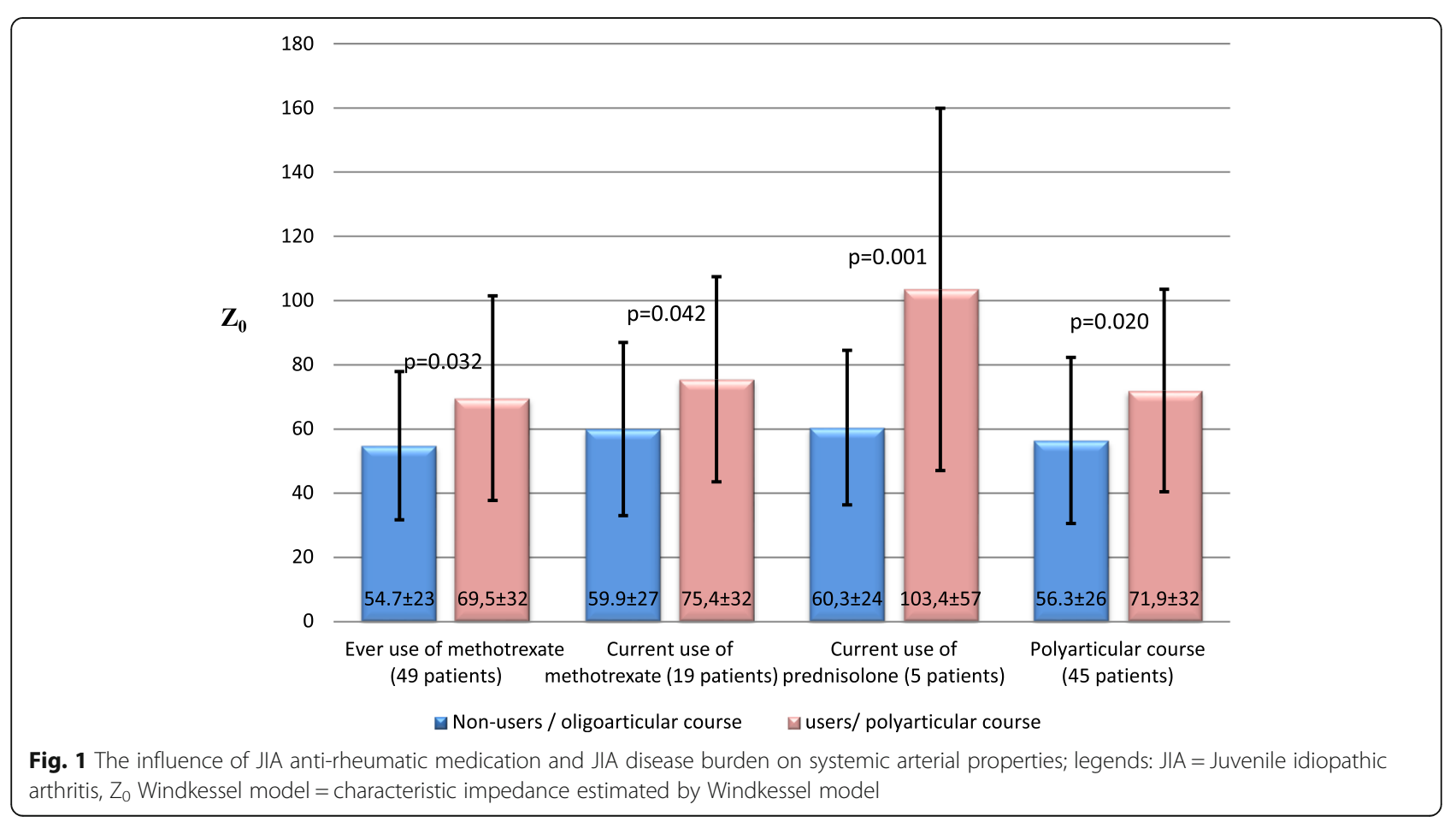


Table 3 Correlations of JIA disease variables, traditional cardiovascular risk factors and arterial properties assessed by $Z_{0}$ Windkessel model

\begin{tabular}{lll}
\hline & $R$ & $P$-value \\
\hline JIA disease variables & & \\
CRP area under the curve $^{\mathrm{a}}$ & 0.095 & 0.402 \\
ESR area under the curve $^{\mathrm{a}}$ & 0.238 & 0.037 \\
Years on daily prednisolone & 0.346 & 0.002 \\
Years on daily NSAIDs & 0.152 & 0.177 \\
Years on daily metotrexat & 0.094 & 0.403 \\
Disease duration & -0.193 & 0.085 \\
JADAS & -0.084 & 0.465 \\
Number of active joints & 0.035 & 0.758 \\
Traditional cardiovascular risk factors & & \\
Age & -0.117 & 0.296 \\
BMI & 0.180 & 0.108 \\
Waist circumference & 0.213 & 0.060 \\
Insulin resistance & 0.273 & 0.015 \\
Daily smoking & 0.072 & 0.526 \\
Vigorous physical activity (hours/ week) & -0.111 & 0.347 \\
Moderate physical activity (hours/ week) & -0.189 & 0.118 \\
\hline
\end{tabular}

Variables assessed at 29-year follow-up unless otherwise stated ${ }^{a}$ Calculated from parameters assessed at 15-year and 29-year follow-up (CRP), disease onset, 15-year and 29-year follow-up (ESR)

$J A$ juvenile idiopathic arthritis, CRP C-reactive protein, ESR erythrocyte sedimentation rate, NSAIDs nonsteroidal anti-inflammatory drugs, JADAS Juvenile Arthritis Disease Activity Score, $B M I$ body mass index

do not think that the difference in arterial properties between the JIA patients and controls can be fully explained by blood pressure variations. On the other hand, increased vascular stiffness predicts incident hypertension [16] underscoring the bidirectional relationship between arterial properties and blood pressures. In our previous study not excluding hypertensive controls we found an increased prevalence of hypertension in the JIA patients as compared to the controls [7].

We found an association between use of antirheumatic medication, polyarticular disease course and higher ESR AUC and insulin resistance and altered arterial properties. Larger prospective controlled studies are needed to identify determinants of altered arterial properties in JIA patients. Our findings add to the previously reported association between prednisolone use and increased arterial stiffness in JIA patients from our cohort [7].

The strengths of this study are the inclusion of a well-defined cohort of JIA patients followed for 29 years and the fact that detailed information of arterial properties has not been presented in JIA patients before. However, the number of included participants was relatively small, and because of a cross sectional study design the prognostic value of our findings is unknown.
In conclusion, our results suggest that adult patients with long-lasting active JIA had stiffer proximal aorta, and lower total arterial compliance but similar systemic resistance compared to matched controls from the general population. Years on daily prednisolone and insulin resistance were the most important correlates of altered arterial properties. Whether our findings indicate that JIA patients should enter a regular BP monitoring program needs to be determined in future longitudinal follow-up studies.

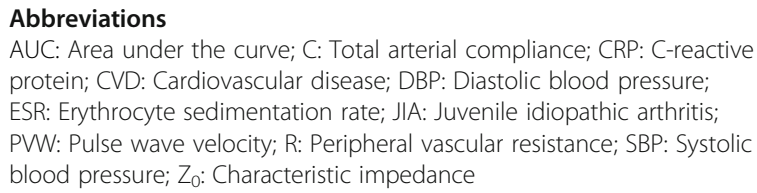

\section{Acknowledgements}

We are indebted to prof. Patrick Segers, IBIT IBiTech-bioMMeda, Ghent University, Belgium for his valuable comments on this manuscript. We would also like to thank Pia Elisabeth Bryde, Richard Massey and Lene Annette Rustad for valuable assistance with echocardiographic and tonometric recordings. Further we thank Torhild Garen for help with preparation of questionnaires, Lars Mørkrid for valuable help obtaining laboratory assessments, and Inge-Margrethe Gilboe and Øyvind Molberg for administrative support.

\section{Funding}

The study was founded by the Norwegian Rheumatism Association science foundation, Consultant Jan A Pahles and Storstuens legat, and the Norwegian ExtraFoundation for Health and Rehabilitation.

\section{Availability of data and materials}

The dataset used and/or analysed during the current study are available from the corresponding author on reasonable request.

\section{Authors' contributions}

HAA organised the study, examined the patients/controls, performed the statistics, wrote the manuscript and developed the tables and figure, MEE, AMS and VL examined the patients and contributed in writing the manuscript, BF conceived and planned the project, examined the patients and supervised the project and contributed to the manuscript, SA contributed to the design of study and the manuscript preparation. All authors read and approved the final manuscript.

\section{Ethics approval and consent to participate}

The study was approved by the Regional Ethics Committee for Medical Research (No.2011/982) and written informed consent according to the declaration of Helsinki (2008) was obtained from all participants.

Consent for publication

Not applicable.

\section{Competing interests}

The authors declare that they have no competing interests.

\section{Publisher's Note}

Springer Nature remains neutral with regard to jurisdictional claims in published maps and institutional affiliations.

\section{Author details}

${ }^{1}$ Department of Rheumatology, Oslo University Hospital, Rikshospitalet, Oslo, Norway. ${ }^{2}$ Department of Internal Medicine, Diakonhjemmet Hospital, Oslo, Norway. ${ }^{3}$ Department of Cardiology, Oslo University Hospital, Rikshospitalet, Oslo, Norway. ${ }^{4}$ Institute for Clinical Medicine, Medical Faculty, University of Oslo, Oslo, Norway. ${ }^{5}$ Department of Circulation and Imaging, Faculty of Medicine and Health Science, Norwegian University of Science and 
Technology, NTNU, Trondheim, Norway. ${ }^{6}$ Clinic of Cardiology, St. Olavs Hospital, Trondheim, Norway.

Received: 1 October 2018 Accepted: 13 December 2018

Published online: 29 December 2018

\section{References}

1. Bertilsson L, Andersson-Gare B, Fasth A, Petersson IF, Forsblad-D'elia

$H$. Disease course, outcome, and predictors of outcome in a population-based juvenile chronic arthritis cohort followed for 17 years. J Rheumatol. 2013;40:715-24.

2. Selvaag AM, Aulie HA, Lilleby V, Flato B. Disease progression into adulthood and predictors of long-term active disease in juvenile idiopathic arthritis, Ann Rheum Dis. 2016;75:190-5.

3. Mitchell GF, Hwang SJ, Vasan RS, Larson MG, Pencina MJ, Hamburg NM, et al. Arterial stiffness and cardiovascular events: the Framingham heart study. Circulation. 2010;121:505-11.

4. Ambrosino P, Tasso M, Lupoli R, Di MA, Baldassarre D, Tremoli E, et al. Noninvasive assessment of arterial stiffness in patients with rheumatoid arthritis: a systematic review and meta-analysis of literature studies. Ann Med. 2015; 47:457-67.

5. Laurent S, Cockroft J, Bortel L, Boutouyrie P, Giannattasio C, Hayoz D, et al. Expert consensus document on arterial stiffness: methodological issues and clinical applications. Eur Heart J. 2006;26:2588-605.

6. Segers $P$, Rietzschel ER, De Buyzere ML, Vermeersch SJ, De BD, Van Bortel LM, et al. Noninvasive (input) impedance, pulse wave velocity, and wave reflection in healthy middle-aged men and women. Hypertension. 2007:49:1248-55.

7. Aulie HA, Selvaag AM, Gunther A, Lilleby V, Molberg O, Hartmann A, et al. Arterial haemodynamics and coronary artery calcification in adult patients with juvenile idiopathic arthritis. Ann Rheum Dis. 2015;74:1515-21.

8. Petty RE, Southwood TR, Manners P, Baum J, Glass DN, Goldenberg J, et al. International league of associations for rheumatology classification of juvenile idiopathic arthritis: second revision, Edmonton, 2001. J Rheumatol. 2004;31:390-2

9. Wallace CA, Ruperto N, Giannini E. Preliminary criteria for clinical remission for select categories of juvenile idiopathic arthritis. J Rheumatol. 2004;31:2290-4.

10. Matthews DR, Hosker JP, Rudenski AS, Naylor BA, Treacher DF, Turner RC Homeostasis model assessment: insulin resistance and beta-cell function from fasting, plasma glucose and insulin concentrations in man. Diabetologia. 1985;28:412-9.

11. Rietzschel ER, De Buyzere ML, Bekaert S, Segers P, De Bacquer D, Cooman L, et al. Rationale, design, methods and baseline characteristics of the Asklepios study. Eur J Cardiovasc Prev Rehabil. 2007;14:179-91.

12. Millar JA, Lever AF, Burke V. Pulse pressure as a risk factor for cardiovascular events in the MRC mild hypertension trial. J Hypertens. 1999;17:1065-72.

13. Blacher J, Staessen JA, Girerd X, Gasowski J, Thijs L, Liu L, et al. Pulse pressure not mean pressure determines cardiovascular risk in older hypertensive patients. Arch Intern Med. 2000;160:1085-9.

14. Lilly SM, Jacobs D, Bluemke DA, Duprez D, Zamani P, Chirinos J. Resistive and pulsatile arterial hemodynamics and cardiovascular events: the multiethnic study of atherosclerosis. In: I am heart Assoc published online: 11 des; 2014. https://doi.org/10.1161/JAHA.114.001223.

15. Cooper LL, Rong J, Benjamin EJ, Larson MG, Levy D, Vita JA, et al. Components of hemodynamic load and cardiovascular events: the Framingham heart study. Circulation. 2015:131:354-61.

16. Dernellis J, Panaretou M. Aortic stiffness is an independent predictor of progression to hypertension in nonhypertensive subjects. Hypertension. 2005;45:426-31.

Ready to submit your research? Choose BMC and benefit from:

- fast, convenient online submission

- thorough peer review by experienced researchers in your field

- rapid publication on acceptance

- support for research data, including large and complex data types

- gold Open Access which fosters wider collaboration and increased citations

- maximum visibility for your research: over $100 \mathrm{M}$ website views per year

At BMC, research is always in progress.

Learn more biomedcentral.com/submissions 